\title{
Impact of Vitamin D deficiency on Rehabilitation Outcome
}

\author{
Wee TC, Galinato P, Lolong $L$ and Pande SD*
}

Department of Rehabilitation Medicine, Changi General Hospital, Singapore

*Corresponding author: Pande SD, Department of Rehabilitation Medicine, Changi General Hospital, Singapore, Tel: 8265945698; E-mail:

shrikantpande@yahoo.co.uk

Received date: July 29, 2016; Accepted date: Sep 23, 2016; Published date: Sep 29, 2016

Copyright: (c) 2016 Wee TC et al. This is an open-access article distributed under the terms of the Creative Commons Attribution License, which permits unrestricted use, distribution, and reproduction in any medium, provided the original author and source are credited.

\begin{abstract}
Vitamin D deficiency, which can result from inadequate sun exposure, dietary intake, or problems with absorption, is rarely documented in the rehabilitation literature. Most likely, it is rarely thought of by the rehabilitation profession. This is problematic because vitamin $D$ deficiency can present as musculoskeletal pain, which is commonly seen in both outpatient clinics and inpatient rehabilitation units. The populations with the greatest risk include the homebound elderly, people with pigmented skin, people with cultural and social avoidance of the sun, people who live in wintertime in climates above and below latitudes of 35 degrees, and people with gastrointestinal absorption.

Vitamin D deficiency should be included in the differential diagnosis in the evaluation of musculoskeletal pain complaints in the rehabilitation setting, and treatment of any identified deficiency should be considered a potentially important component of the treatment regimen.
\end{abstract}

\section{Introduction}

25-hydroxyitamin $\mathrm{D}$ deficiency is common amongst various populations worldwide. As per previous studies the prevalence of vitamin $\mathrm{D}$ deficiency varies greatly due to differences in definitions used and it ranged from $57 \%$ to $74 \%$ in in-patient medical population $[1,2] .70 .3 \%$ and $67 \%$ of an acute inpatient rehabilitation population and outpatient rehabilitation population respectively were found to have a serum 25-hydroxyvitamin D of less than $30 \mathrm{ng} / \mathrm{ml}[3,4]$. Vitamin D deficiency has been classically recognized for its role in bone health, however there is increasing evidence of its role in extraskeletal health. Investigators of most prospective studies reported moderate to strong inverse associations between $25(\mathrm{OH})$ D concentrations and cardiovascular diseases, serum lipid concentrations, inflammation, glucose metabolism disorders, weight gain, infectious diseases, multiple sclerosis, mood disorders, declining cognitive function, impaired physical functioning, and all-cause mortality [5].

There have been several studies published on the vitamin D status of rehabilitation patients except one study none of them included significant number of patients from Asia [6].

We therefore, performed this pilot study with the primary objective of determining the prevalence of vitamin D screening and association of vitamin D status with functional outcome in a sampling of patients in an in-patient rehabilitation unit tertiary care hospital in Singapore. A secondary objective was to evaluate variables that may influence vitamin D status.

\section{Methods}

The rehabilitation unit is located within the campus of a regional hospital and is well equipped with all the modern facilities for both in and out patient referrals. The majority of patients referred are stroke, acquired brain injury, spinal cord injury and complex medical and post-surgical deconditioning.
This is a retrospective cohort study involving the review of electronic medical records of all patients discharged from a general rehabilitation inpatient unit located within a general hospital in Asia. The review period was from 1st July 2014 to 30th June 2015. Medical records of patients discharged within the review period were screened for serums 25-hydroxyvitamin D results which were obtained during the same admission. Patients with end stage renal failure on dialysis or stage $\mathrm{V}$ chronic kidney disease were then excluded.

Demographic data (age, gender, race), primary rehabilitation diagnosis, length of stay, discharge destination, medical comorbidities, body mass index, bone mineral densitometry, Functional Independence Measure (FIM) on admission and discharge and serum 25-hydroxyvitamin D level for each patient were collected.

In this study, we have defined vitamin D deficiency based on the Endocrine Society Clinical Practice Guideline, which is that of a serum 25-hydroxyvitamin D level less than $20 \mathrm{ng} / \mathrm{ml}$.

The FIM is a functional assessment tool commonly used in the inpatient rehabilitation setting. Eighteen different activities (13 motor, 5 cognitive) are scored on a scale of 1 to 7 , with a score of 1 indicating complete dependence and 7 indicating complete independence. By adding the scores for each subscale, a total score can range from 18 points (lowest possible level of functional independence) to 126 points (highest possible level of functional independence). FIM efficiency is calculated by dividing the difference in discharge and admission FIM scores by inpatient rehabilitation length of stay [6].

Statistical analysis was performed using SPSS 19 statistical software, version 19.0 (IBM Corp. Armonk, NY) and statistical significance is set at $\mathrm{p}<0.05$. Categorical data is presented as frequency (percentage). Numeric data is presented as mean (standard deviation) for parametric distribution and median (interquartile range) for non-parametric distribution. The differences in characteristics were examined using Chi-Square test for categorical variables and 2-sample t-test for continuous variables. 
Citation: Wee TC, Galinato P, Lolong L, Pande SD (2016) Impact of Vitamin D deficiency on Rehabilitation Outcome. J Diabetes Metab 7: 704.

Page 2 of 3

This study is approved by the Singhealth Centralised Institutional Review Board.

\section{Results}

There were a total of 746 patients discharged from the inpatient rehabilitation unit from 1st July 2014 to 30th June 2015. Out of these, 52 patients had serum vitamin D levels checked during their admission of the 52 patients with vitamin D levels available, 29 (55.8\%) patients were found to be vitamin D deficient (less than $20 \mathrm{ng} / \mathrm{ml}$ ). Within these 29 vitamin D deficient patients: $38.5 \%$ were post stroke, $32.7 \%$ were admitted for medical or surgical deconditioning (Table 1).

\begin{tabular}{|c|c|}
\hline Characteristics & $\mathrm{N}=52(\%)$ \\
\hline \multicolumn{2}{|l|}{ Gender } \\
\hline Male & $23(44.2)$ \\
\hline Female & $29(55.8)$ \\
\hline \multicolumn{2}{|l|}{ Race } \\
\hline Chinese & $43(82.7)$ \\
\hline Malay & $7(13.5)$ \\
\hline Indian & $2(3.8)$ \\
\hline Mean Age [range] & 70.4 [15 to 89$]$ \\
\hline \multicolumn{2}{|l|}{ Rehabilitation diagnosis } \\
\hline Stroke & $20(38.5)$ \\
\hline Trauma & $5(9.6)$ \\
\hline Deconditioning & $17(32.7)$ \\
\hline TBI & $1(1.9)$ \\
\hline Amputee & $1(1.9)$ \\
\hline Others & $8(15.4)$ \\
\hline \multicolumn{2}{|l|}{ Nursing home patient } \\
\hline Yes & $3(5.8)$ \\
\hline No & $49(94.2)$ \\
\hline \multicolumn{2}{|l|}{ Ambulatory status } \\
\hline Community ambulant & $30(57.7)$ \\
\hline Home bound & $22(42.3)$ \\
\hline \multicolumn{2}{|l|}{ Working } \\
\hline Yes & $7(13.5)$ \\
\hline No & $45(86.5)$ \\
\hline \multicolumn{2}{|l|}{ Admitted to ICU } \\
\hline Yes & $7(13.5)$ \\
\hline No & $45(86.5)$ \\
\hline \multicolumn{2}{|l|}{ Discharge destination } \\
\hline Home & $29(55.8)$ \\
\hline Community hospital & $17(32.7)$ \\
\hline Nursing home & $4(7.7)$ \\
\hline Others & $2(3.8)$ \\
\hline \multicolumn{2}{|l|}{ Vitamin $D<20 \mathrm{ng} / \mathrm{ml}$} \\
\hline Yes & $29(55.8)$ \\
\hline No & $23(44.2)$ \\
\hline
\end{tabular}

Table 1: Clinical characteristics of patients.
A number of patients' characteristics including rehabilitation outcome were analysed. Patients with Vitamin D deficiency achieved lower total FIM gain during inpatient rehabilitation. A greater proportion of darker skin patients (Malay and Indians) were found to be Vitamin D deficient. However, none of them reached statistical significance (Table 2).

\begin{tabular}{|c|c|c|c|}
\hline Characteristics & $\begin{array}{l}\text { Vitamin } \\
D>=20\end{array}$ & $\begin{array}{l}\text { Vitamin } \\
D<20\end{array}$ & $P$ value \\
\hline Age & 71.0 & 69.9 & NS \\
\hline Albumin & 31.6 & 31.6 & NS \\
\hline Haemoglobin & 12.6 & 12.7 & NS \\
\hline Total FIM gain & 11.0 & 8.1 & NS \\
\hline Motor FIM gain & 8.0 & 6.2 & NS \\
\hline Cognitive FIM gain & 1.8 & 1.2 & NS \\
\hline $\mathrm{BMI}$ at admission & 23.6 & 21.1 & NS \\
\hline LOS & & & \\
\hline Total & 34 & 32 & NS \\
\hline Rehabilitation & 26 & 23 & NS \\
\hline Gender & & & \\
\hline Male & 7 & 16 & \\
\hline Female & 16 & 13 & NS \\
\hline Race & & & \\
\hline Chinese & 22 & 21 & \\
\hline Malay & 1 & 6 & \\
\hline Indian & 0 & 2 & NS \\
\hline Ambulatory Status & & & \\
\hline Homebound & 10 & 12 & \\
\hline Community ambulant & 13 & 17 & NS \\
\hline Working & & & \\
\hline Yes & 4 & 3 & \\
\hline No & 19 & 26 & NS \\
\hline ICU admission & & & \\
\hline Yes & 4 & 3 & \\
\hline No & 19 & 26 & NS \\
\hline $\begin{array}{l}\text { Presence of } 3 \text { cardiovascular } \\
\text { risk factors }^{*} \\
\text { Yes } \\
\text { No }\end{array}$ & $\begin{array}{l}4 \\
19\end{array}$ & $\begin{array}{l}7 \\
22\end{array}$ & NS \\
\hline Diagnosed osteoporosis & & & \\
\hline Yes & 4 & 6 & \\
\hline No & 19 & 23 & NS \\
\hline Osteoporotic fracture & & & \\
\hline Yes & 5 & 7 & \\
\hline No & 18 & 22 & NS \\
\hline
\end{tabular}

Table 2: Comparison of parameters between vitamin D deficient and non-deficient groups; NS: Not Significant. 


\section{Discussion}

In our pilot study $55.8 \%$ patients were found to have vitamin D deficiency. Vitamin D deficiency is a significant problem in the inpatient rehabilitation patients even in tropical Singapore where there is abundant sunshine year round.

Previous studies examining the association between vitamin D deficiency and rehabilitation outcomes had been published. A prospective study by Klebzak et al. $[7,8]$ done in a general rehabilitation unit of a hospital located in the United States, that length of stay and FIM efficiency were favorably affected by higher vitamin D level.

However, in another study from the United States, unadjusted total FIM efficiency scores were statistically significant in association with vitamin D status.

Vitamin D status was not significant factor in relation to the total FIM efficiency score after controlling for demographic and clinical factors. In our pilot study, there was a trend towards a larger total FIM gain in patients with normal vitamin $\mathrm{D}$ level group as compared to the vitamin $\mathrm{D}$ deficient group, although this difference was statistically insignificant.

It was found in a prospective cohort study from Singapore that age, gender, vitamin D supplementation, premorbid ambulatory status, and admission/discharge FIM scores were not significantly associated with vitamin D deficiency. Malays, Indians and patients with recurrent falls were at higher risks for vitamin D deficiency [9]. The findings were largely in congruent with the our pilot study, apart from the racial difference.

In another prospective study, Gradel demonstrated an association between vitamin $\mathrm{D}$ insufficiency and deficiency with adverse clinical and functional outcomes. $68 \%$ of patients attending rehabilitation outpatient clinics who were not on vitamin D supplementation were either vitamin $\mathrm{D}$ insufficient or deficient. This suggests that vitamin $\mathrm{D}$ deficiency is not just confined to the rehabilitation in-patients.

The question remains whether vitamin D supplementation translates to clinical benefits. Results from a recent review by Grädel et al. [10] showed that high-quality evidence from interventional trials on the benefits of vitamin D supplementation in inpatients is currently lacking. The authors concluded that vitamin $\mathrm{D}$ screening and supplementation for the medical inpatient population in an acute care setting cannot be recommended based on current available evidence.

There is evidence to support an association between high body mass index and vitamin D deficiency. A study consisting of well community dwelling adults in Asia showed that higher BMI and larger waist circumference were significantly associated with lower vitamin D levels. There was a trend towards a higher BMI for patients who were vitamin $\mathrm{D}$ deficient however these results were not statistically significant.

\section{Limitations of our study}

It is a retrospective pilot study and some of the data was incomplete. The sample size is small and hence it may not represent all rehabilitation inpatients. The patients who had serum 25hydroxyvitamin $\mathrm{D}$ levels obtained during their inpatient stay were more likely to be identified as having high risk for deficiency [11]. As the majority of the patients did not have vitamin D levels done, the comparison of these two groups was not possible.

\section{Conclusion}

A systematic prospective study may be helpful on Asian population, in both inpatient and outpatient rehabilitation setting to determine the prevalence of vitamin $\mathrm{D}$ deficiency. This can also then determine the cost effectiveness of screening the inpatient rehabilitation population.

\section{References}

1. Brand ck (1998) Hypovitaminosis D in medical inpatients. N Engl J Med 338: 777-783.

2. Holick MF, Binkley NC, Bischoff-Ferrari HA, Gordon CM (2011) Endocrine Society. Evaluation, treatment and prevention of vitamin D deficiency: an Endocrine Society clinical practice guideline. J Clin Endocrinol Metab 96: 1911-1930.

3. Chatfield SM, Brand C, Ebeling PR, Russell DM (2007) Vitamin D deficiency in general medical inpatients in summer and winter. Intern Med J 37: 377-382.

4. Pellicane AJ, Wysocki NM, Malison TR, Schnitzer TZ (2011) Prevalence of 25-hydroxyvitamin $\mathrm{D}$ deficiency in the acute inpatient rehabilitation population and its effect of function. Arch Phys Med Rehab 92: 705-711.

5. Pellicane AJ, Wysocki NM, Schnitzer TJ (2010) Prevalence of 25hydroxyvitamin D deficiency in the outpatient rehabilitation population. Am J Phys Med Rehabil 89: 899-904.

6. Autier P, Boniol M, Pizot C, Mullie P (2014) Vitamin D status and ill health: a systematic review. Lancet Diabetes Endocrion 2: 76-89.

7. Ottenbacher KJ, Hsu Y, Granger CV, Fiedler RC (1996) The reliability of the functional independence measure: a quantitative review. Arch Phys Med Rehab 77: 1226-1232.

8. Kiebzak GM, Moore NL, Margolis S, Hollis B, Kevorkian CG (2007) Vitamin D status of patients admitted to a hospital rehabilitation unit: relation to function and progress. Am J Phys Med Rehabil unit: relation to function and progress. Am J Phys Med Rehab 86: 435-445.

9. Neo JJ, Kong KH (2016) Prevalence of Vitamin D Deficiency in Elderly Patients Admitted to an Inpatient Rehabilitation Unit in Tropical Singapore. Rehabil Res Pract 22.

10. Gradel L, Merker M, Felder S, Kutz A (2016) Vitamin D Deficiency Strongly Predicts Adverse Medical Outcomes Across Different Medical Inpatient Populations: Results from a Prospective study. Medicine (Baltimore) 19: 3533.

11. Grädel L, Merker M, Mueller B, Schuetz P (2016) Screening and treatment of Vitamin D Deficiency on Hospital admission. Is there a benefit for medical inpatients? AM j Med 129: 116. 